\section{The Effect of Breaking Properties and Fragmentation on the Perceived Saltiness of Surimi Gels Prepared with Various Heating Conditions}

\author{
Thi My Hanh Tran ${ }^{1,3}$, Kaoru Kohyama ${ }^{2}$, Kazufumi Osako ${ }^{1}$ and Emiko Okazaki ${ }^{*}$ \\ ${ }^{1}$ Department of Food Science and Technology, Tokyo University of Marine Science and Technology, Japan \\ ${ }^{2}$ Food Research Institute, National Agriculture and Food Research Organization, Japan \\ ${ }^{3}$ Faculty of Food Technology, Nha Trang University, Vietnam
}

"Corresponding author: Emiko Okazaki, Department of Food Science and Technology, Tokyo University of Marine Science and Technology, Konan 4-5-7, Minato-ku, Tokyo 108-8477, Japan, Tel: +81-3-5463-0618; Fax: +81-3-5463-0618; E-mail: eokazaki@kaiyodai.ac.jp

Received date: March 14, 2017; Accepted date: April 11, 2017; Published date: April 20, 2017

Copyright: ( 2017 Tran TMH, et al. This is an open-access article distributed under the terms of the Creative Commons Attribution License, which permits unrestricted use, distribution, and reproduction in any medium, provided the original author and source are credited.

\begin{abstract}
The strength of taste is thought to be affected not only by content of food, but also by the texture. The previous study on the relationship between the saltiness and texture of heat-induced surimi gels prepared with different setting conditions revealed that the difference of physical properties did not affect the perceived saltiness of surimi gels, notwithstanding the breaking strength was very different according to the setting time. This result was seemed to contradict to the findings obtained with other food material so far. Therefore, this study was aimed to clarify the relationship between the intensity of saltiness and texture of heat-induced surimi-based products focusing on the fragmentation of the gel. To prepare various types of surimi gels having different physical properties from the same material, surimi gels were prepared by 2-steps heating with different level of pre-heating at $60^{\circ} \mathrm{C}$ (modori). The physical properties of surimi gels were evaluated by puncture test, two-bite texture profile analysis and measurement of expressible water. The particle size of surimi gels after chewing in mouth by every panelist was also evaluated. The physical properties of heat-induced surimi gels became softer and more fragile according to the preheating time at $60^{\circ} \mathrm{C}$. Maximum saltiness intensity in the gel was evaluated comparing with different reference solutions. The result of the sensory evaluation suggested that the difference in physical properties derived by heat induced degradation during pre-heating at $60^{\circ} \mathrm{C}$ affected the perceived saltiness during consumption of surimi gels, and that the fragmentation of the gel will strongly correlate to the perceived saltiness of surimi gels.
\end{abstract}

Keywords: Surimi-based product; Breaking properties; Fragmentation; Modori gel; Pre-heating; Texture; Saltiness; Sensory evaluation

\section{Introduction}

It is thought that differences in the texture or structure of solid foods affect the perception of taste during mastication [1]. However, there is little information about the physical factors that affect the saltiness of surimi-based products. To clarify the relationship between the physical properties and perceived saltiness of surimi-based products, heat-induced surimi gels with various setting (preheating at $30^{\circ} \mathrm{C}$ ) conditions were prepared and the perceived saltiness was determined in the previous study [2]. The results indicated that the differences in physical properties do not affect the saltiness of surimi gels, despite substantial differences in breaking strength, breaking strain, and water holding capacity among setting times. It was suggested that the phenomenon would be influenced by not only the characteristics of the texture obtained by setting but also the salt concentration in the gel, and that it should be carefully concluded whether the texture affect the saltiness efficiency of surimi gel or not.

Some studies indicated that an increase in hardness (represented by the fracture stress) for solid and semi-solid foods [3] decrease perceived flavor intensity. For solid and semi-solid foods, an increase in textural brittleness (represented by the fracture strain) also increases perceived flavor intensity $[4,5]$.
It has been also reported that, when a product is consumed, many variables will affect its taste perception, such as mastication rate [6], ingredient interactions [7] and taste adaptation [8] yet this variation often remains unnoticed in the overall flavour perception $[9,10]$. Perceived sweetness of solid foods (meringue, candy, cookie, chocolate, and Youkan) containing $7.8 \%-80 \%(\mathrm{w} / \mathrm{w})$ sucrose was equivalent to that of $6.7 \%-25.7 \%(\mathrm{w} / \mathrm{w})$ sucrose solutions [11]. Shimada et al. [11] found that the sweetness of chewed samples was affected not only by sucrose content but also by the increasing rate of surface area, amount of saliva, and water absorption.

Taste of solid foods including gels is not sensed immediately when the food is inserted into the mouth. Mastication is required for taste perception. Sour taste of gummy jellies was perceived after some chews, increased the intensity with time, and was remained sometime after the food bolus was swallowed [12]. Sucrose release was less with harder agar gels containing similar sucrose [13]. The harder gels were chewed more with longer period and sweetness was more slowly sensed during mastication [14].

Surimi gels required considerable numbers of chews as stated in the preceding study [2], salt release and perceived saltiness of those gels may be more influenced by repeated bites than by the breaking properties determined with puncture test. More chews would produce greater numbers of gel particles with smaller sizes in the bolus. Therefore, in this study, the relationship between the saltiness and texture of heat-induced surimi gels was more precisely examined, with a focus on the fragmentation of the gel using 2-step heated gels with various pre-heating times at $60^{\circ} \mathrm{C}$. 
Citation: Tran TMH, Kohyama K, Osako K, Okazaki E (2017) The Effect of Breaking Properties and Fragmentation on the Perceived Saltiness of Surimi Gels Prepared with Various Heating Conditions. J Exp Food Chem 3: 125. doi:10.4172/2472-0542.1000125

Page 2 of 6

\section{Materials and Methods}

\section{Preparation of washed surimi gels}

Frozen Alaska pollock surimi (FA grade, Maruha Nichiro Corporation, Japan) blocks (10 kg) were used as material. To remove the effect of additives which are contained in surimi such as sucrose and/or sorbitol, etc., washed surimi was prepared according to the method in the previous study [2].

The water content of washed surimi was adjusted to $87 \%(\mathrm{w} / \mathrm{w})$, and $\mathrm{NaCl}$ was added $(1 \%, 2 \%$ and $3 \%(\mathrm{w} / \mathrm{w})$ final concentration) in refrigerated vacuum cutter operated at $300 \mathrm{rpm}$ for $4 \mathrm{~min}$. The temperature was maintained below $10^{\circ} \mathrm{C}$.

The salt-ground paste was stuffed into polyvinylidene chloride casing tube $(30 \mathrm{~cm}$ in length and $23 \mathrm{~mm}$ in diameter; Kureha Chemical Industry Co., Ltd., Nishiki, Japan) and incubated in water baths at $60^{\circ} \mathrm{C}$ for $0,20,60,120 \mathrm{~min}$ followed by second heating at 90 for $30 \mathrm{~min}$ (2-step heating). After heating, the gel was cooled immediately in ice water overnight. The measurement of physical properties and water holding capacity, and sensory evaluation were performed.

\section{Puncture test}

Puncture test was performed as same as the previous study [2] according to the method proposed by CODEX [15-17].

\section{Two-bite texture profile analysis}

This is a popular double compression test for determining the textural properties of foods. The gel samples $(23 \mathrm{~mm}$ in diameter and $25 \mathrm{~mm}$ in height) were placed between two flat plates of a texture analyzer (Rheoner II, RE2-33005B, Yamaden Co., Ltd, Tokyo, Japan) with a cell load of $20 \mathrm{~N}$. A two-bite compression test was performed up to $25 \%$ of the original height at a deformation rate of $1 \mathrm{~mm} / \mathrm{s}$. Parameters measured were hardness $(\mathrm{Pa})$, cohesiveness, and adhesiveness $\left(\mathrm{J} / \mathrm{m}^{3}\right)$ [15-17]. Each measurement was conducted 10 times and the highest and lowest values were omitted.

\section{Water holding capacity}

The water holding capacity of the gel was determined by the amount of expressible water as same as the previous study [2].

\section{Sensory evaluation}

Sensory analyses of gels were conducted as the same method as the previous study [2]. Gel samples were cut into $1.00 \pm 0.05 \mathrm{~g}(23 \mathrm{~mm}$ in diameter and $10 \mathrm{~mm}$ in height, divided into 4 small pieces) and 2 replicates (with three-digit codes without information about the sample) were presented in a random order to every panelist. Reference solutions with different $\mathrm{NaCl}$ concentrations were prepared. Water, 0.322 and $0.519 \%(\mathrm{w} / \mathrm{w})$ was used as references $(0,5,10$ points, respectively) for gel adding $1 \% \mathrm{NaCl}$. Water, 0.512 and $0.825 \%(\mathrm{w} / \mathrm{w})$ was used as references $(0,5,10$ points, respectively) for gel adding $2 \%$ $\mathrm{NaCl}$. Water, 0.659 and $1.061 \%(\mathrm{w} / \mathrm{w})$ was used as references $(0,5,10$ points, respectively) for gel adding $3 \% \mathrm{NaCl}$. In every session, the panelist was received 4 samples with three-digit numbers without information about the samples, evaluated the maximum saltiness intensity of every sample during mastication until swallowing comparing the saltiness with 3 reference solutions.

\section{Measurement of fragmentation of surimi gels}

Each panelist masticated $3 \mathrm{~g}$ of surimi gel by 10 times without swallowing. To collect the surimi gel fragments, panelists were asked to spit the fragments into a beaker after chewed the fixed number of chews. Gel fragments were collected two times per panelist for each condition. The panelists rinsed their mouths with water to entirely remove all fragments. The gel fragments and water were carefully stirred in a beaker using a glass rod and passed through a sieve with a mesh size of $0.5 \mathrm{~mm}$. After fine fragments were washed through the sieve with running water, the fragments on the sieve were spread evenly on black paper with a plastic cover $(210 \times 297 \mathrm{~mm})$, a print image of fragments was made using a copy machine [18], and all images were analyzed using WinROOF ver 6.3.5 [19] to determine the number of fragments and total area of fragments.

\section{Statistical analysis}

All instrumental determinations were performed in quadruplicate, at minimum. Data are expressed as means \pm standard deviations. Differences were evaluated using Duncan's multiple range tests. Level of significance was set at $\mathrm{p}<0.05$. Analyses were performed using SPSS software (SPSS 16.0 for Windows). The sensory evaluation data were analyzed using PanelCheck V.1.4.0 [20].
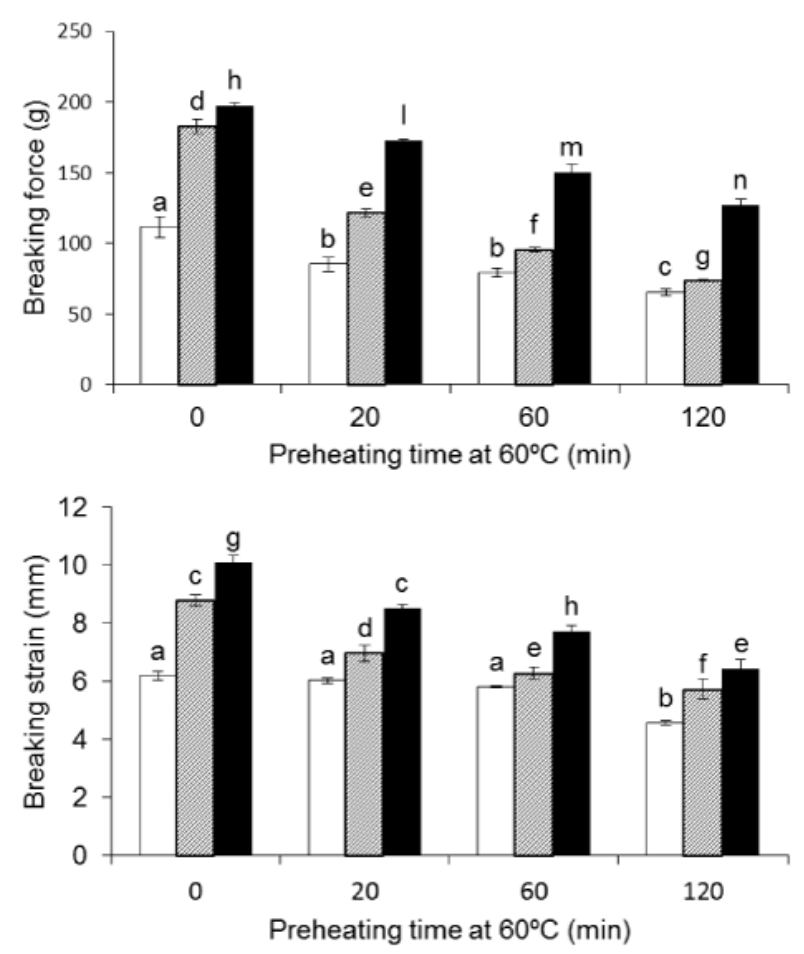

Figure 1: Breaking force and strain of 2-step heated gels with various preheating time at $60^{\circ} \mathrm{C}$. Open bars, diagonal bars, closed bars: surimi gels with $1,2,3 \%(\mathrm{w} / \mathrm{w}) \mathrm{NaCl}$ respectively. Gel with different alphabetical letters differ significantly $(\mathrm{p}<0.05)$. 
Citation: Tran TMH, Kohyama K, Osako K, Okazaki E (2017) The Effect of Breaking Properties and Fragmentation on the Perceived Saltiness of Surimi Gels Prepared with Various Heating Conditions. J Exp Food Chem 3: 125. doi:10.4172/2472-0542.1000125

Page 3 of 6

\section{Results and Discussion}

\section{Breaking force and breaking strain}

Two-step heated gels with different physical properties were prepared by pre-heating at $60^{\circ} \mathrm{C}$ for $0-120 \mathrm{~min}$, followed by a second heating at $90^{\circ} \mathrm{C}$ for $30 \mathrm{~min}$. The breaking force and breaking strain results obtained in the puncture test are shown in Figure 1. The gel strength increased with addition of $\mathrm{NaCl}$, especially, the breaking force and strain for $3 \% \mathrm{NaCl}$ gels were much higher than those for lower $\mathrm{NaCl}$ gels. The breaking force and breaking strain gradually decreased as the pre-heating time increased at $60^{\circ} \mathrm{C}$, regardless of the $\mathrm{NaCl}$ content in gels. This results close to the reported from Luo et al. [21], the breaking force of $60^{\circ} \mathrm{C}$ incubation was lower than for other temperatures, and decreased as the incubation period increased, and was significantly lower $(\mathrm{p}<0.05)$ at 60 and 120 min incubation than for no incubation. The trends observed for the breaking distance of Alaska pollock surimi were similar to the trends observed for the breaking force [22]. This trend also found in meat chicken surimi.

The gel strength of surimi from chicken meat at $60^{\circ} \mathrm{C}$ increased slightly at $30 \mathrm{~min}$, but then continued to decrease with longer setting times and modori (gel degradation) phenomena occur during the gel formation of surimi. The temperature of modori stage of this surimi is 60 to $70^{\circ} \mathrm{C}[23]$.

Breaking force of directly heated gel was higher than that of modori gel $(\mathrm{p}<0.05)$ in agreement with results reported from yellow stripe trevally surimi [23]. In modori gel the lower breaking force was measured $(p<0.05)$. It was caused by hydrolysis of the protein molecules due to fish muscle proteinases activation at temperature range from $60-65^{\circ} \mathrm{C}[24-26]$. This pattern of texture deterioration was thought to mainly result from the enzymatic degradation of myofibrillar protein [15].

\section{Two-bite texture profile analysis}

The results of a two-bite texture profile analysis are shown in Figure 2. A similar salt effect was observed, though all gels were not broken under 25\% compression. Hardness and cohesiveness decreased, while adhesiveness increased with an increase in the preheating time at $60^{\circ} \mathrm{C}$. Larger differences with respect to preheating time at $60^{\circ} \mathrm{C}$ were obtained for the puncture test than for the two-bite texture profile analysis. This may be explained by the degree of deformation that the former is a destructive test, while the latter is a compression test, without the destruction of samples. This is close to previous study, there was a decrease in hardness when setting sol was prolonged at $60^{\circ} \mathrm{C}$. When cohesiveness value reached closed to 1 , it is indicating that the intactness of sample is high after first compressing cycle of the texture profile analysis. From the results, lower cohesiveness values was obtained from modori gel, suggesting that the gel has a lower tendency of recovery to its original structure after first compressing, compared to suwari gels $(\mathrm{p}<0.05)$ [27].

\section{Water holding capacity}

Figure 3 shows the changes in expressible water over time in 2-step heated gels with pre-heating at $60^{\circ} \mathrm{C}$. Water holding capacity of $1 \%$ $\mathrm{NaCl}$ gels was much lower than that of $2 \%$ and $3 \%$ gels. With an increase in the pre-heating time, expressible water increased, regardless of salt content. The high expressible drip was recorded in modori gel $(\mathrm{p}<0.05)$, indicating the lowest protein-protein bonds water binding capacity of these gels $[28,29]$.
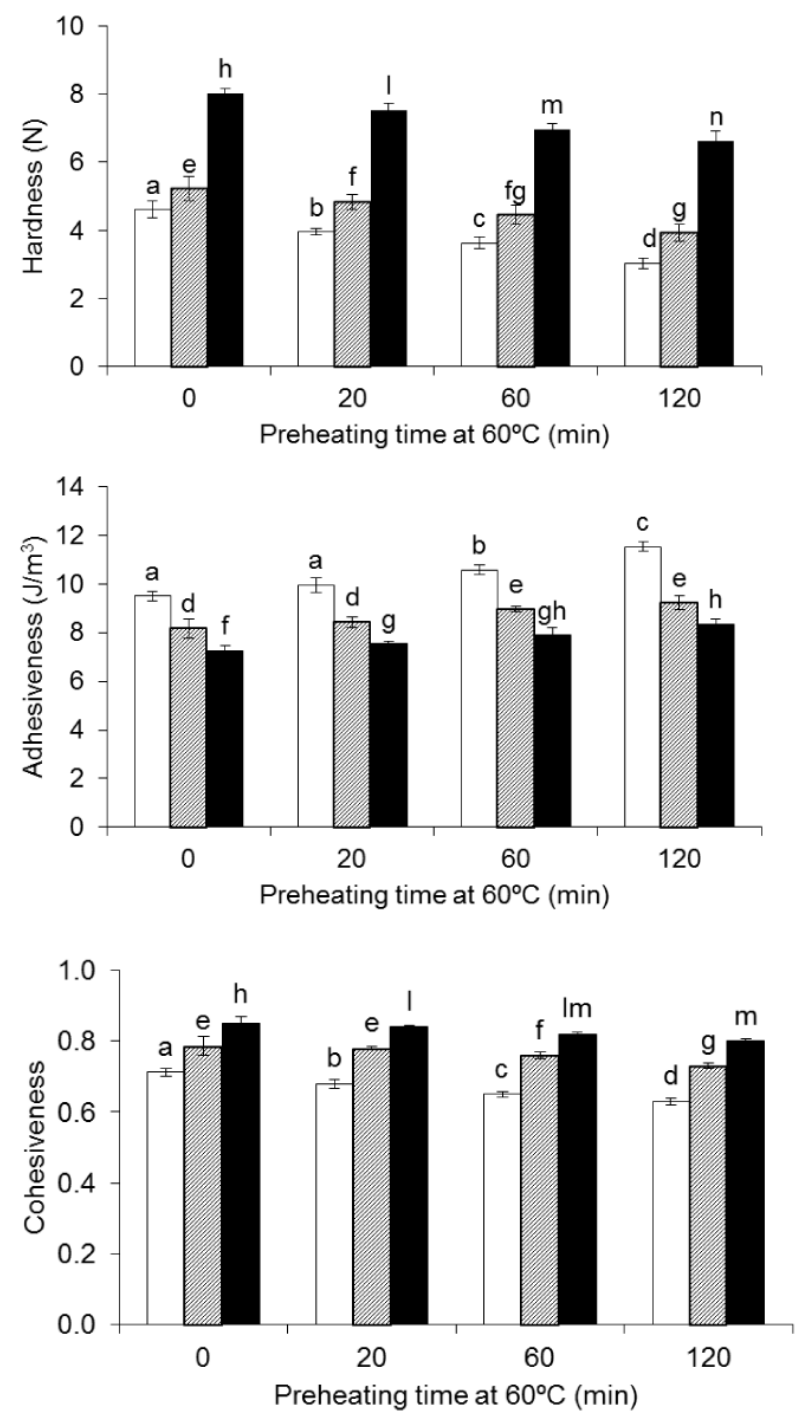

Figure 2: Two-bite texture profile analysis of 2-step heated gels with various preheating time at $60^{\circ} \mathrm{C}$. Open bars, diagonal bars, closed bars: surimi gels with $1,2,3 \%(\mathrm{w} / \mathrm{w}) \mathrm{NaCl}$ respectively. Gel with different alphabetical letters differ significantly $(\mathrm{p}<0.05)$.

\section{Sensory evaluation}

The sensory data for heat-induced gels prepared with different preheating times $(0,20,60$, and $120 \mathrm{~min})$ and $\mathrm{NaCl}$ contents $(1 \%, 2 \%$ and $3 \%)$. These results clearly showed that the saltiness was dependent not only on the $\mathrm{NaCl}$ content, but also on the preheating time at $60^{\circ} \mathrm{C}$. With increase in the pre-heating time, the maximum intensity $\left(I_{\max }\right)$ value became higher. In the gels with 1,2 and $3 \% \mathrm{NaCl}$, the $I_{\max }$ increased from $0.25 \%$ to $0.36 \%, 0.40 \%$ to $0.63 \%$, and $0.63 \%$ to $0.87 \%$, respectively, as the increase of preheating time increased from 0 to 120 $\min$ (Table 1). 
Citation: Tran TMH, Kohyama K, Osako K, Okazaki E (2017) The Effect of Breaking Properties and Fragmentation on the Perceived Saltiness of Surimi Gels Prepared with Various Heating Conditions. J Exp Food Chem 3: 125. doi:10.4172/2472-0542.1000125

Page 4 of 6

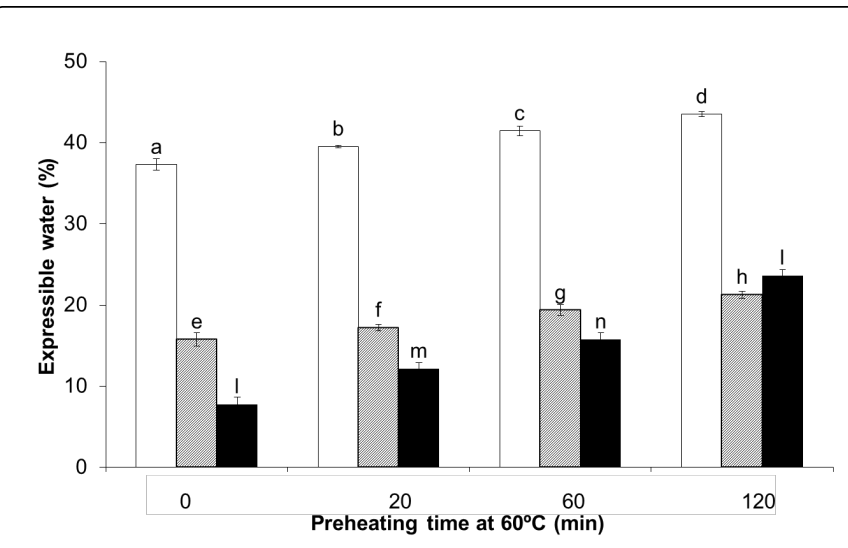

Figure 3: Expressible water of 2-step heated gels with various preheating time at $60^{\circ} \mathrm{C}$. Open bars, diagonal bars, closed bars: surimi gels with $1,2,3 \%(\mathrm{w} / \mathrm{w}) \mathrm{NaCl}$ respectively. Gels with different alphabetical letters differ significantly $(\mathrm{p}<0.05)$.

\begin{tabular}{|l|l|l|l|l|}
\hline \multirow{2}{*}{$\mathrm{NaCl}$} & \multicolumn{4}{|l|}{ Preheating time at $60^{\circ} \mathrm{C}(\mathrm{min})$} \\
\cline { 2 - 5 } & $\mathbf{0}$ & $\mathbf{2 0}$ & 60 & 120 \\
\hline $1 \%(\mathrm{w} / \mathrm{w})$ & $0.25^{\mathrm{a}}$ & $0.29^{\mathrm{ab}}$ & $0.33^{\mathrm{bc}}$ & $0.36^{\mathrm{c}}$ \\
\hline $2 \%(\mathrm{w} / \mathrm{w})$ & $0.40^{\mathrm{d}}$ & $0.46^{\mathrm{e}}$ & $0.57^{\mathrm{f}}$ & $0.63^{\mathrm{g}}$ \\
\hline $3 \%(\mathrm{w} / \mathrm{w})$ & $0.63^{\mathrm{h}}$ & $0.69^{\mathrm{l}}$ & $0.79^{\mathrm{m}}$ & $0.87^{\mathrm{n}}$ \\
\hline
\end{tabular}

Table 1: Maximum saltiness intensity $\left(I_{\max }\right)$ of 2-steps heated gels with various pre-heating time at $60^{\circ} \mathrm{C}$. Values are average of 11 trained panelists with 2 repetitions. Values followed by different alphabetical letters within a row indicate a significant differences $(\mathrm{p}<0.05)$.

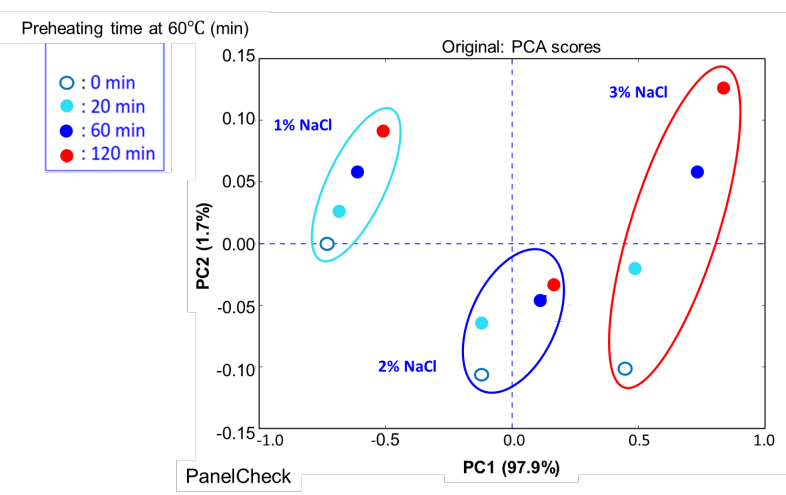

Figure 4: PCA describing saltiness of 2-step heated gels with various preheating time at $60^{\circ} \mathrm{C}$.

We confirmed that the perceived saltiness was affected by the preheating time at $60^{\circ} \mathrm{C}$ by a principal component analysis (PCA), as shown in Figure 4 PCA was applied to analyze all saltiness values for 12 samples during mastication for all panelists with 2 replicates. The first and the second principal components explained $97.9 \%$ and $1.7 \%$, respectively, of the total variance in the saltiness of the 12 samples (2step heated gels with various pre-heating times at $60^{\circ} \mathrm{C}$ ). It is very clear that salt content principally determined saltiness. When the saltiness of gels with similar salt content by being divided into three groups (1\%, $2 \%$ and $3 \% \mathrm{NaCl}$ ) were compared, it clearly differed among samples prepared with different pre-heating times.

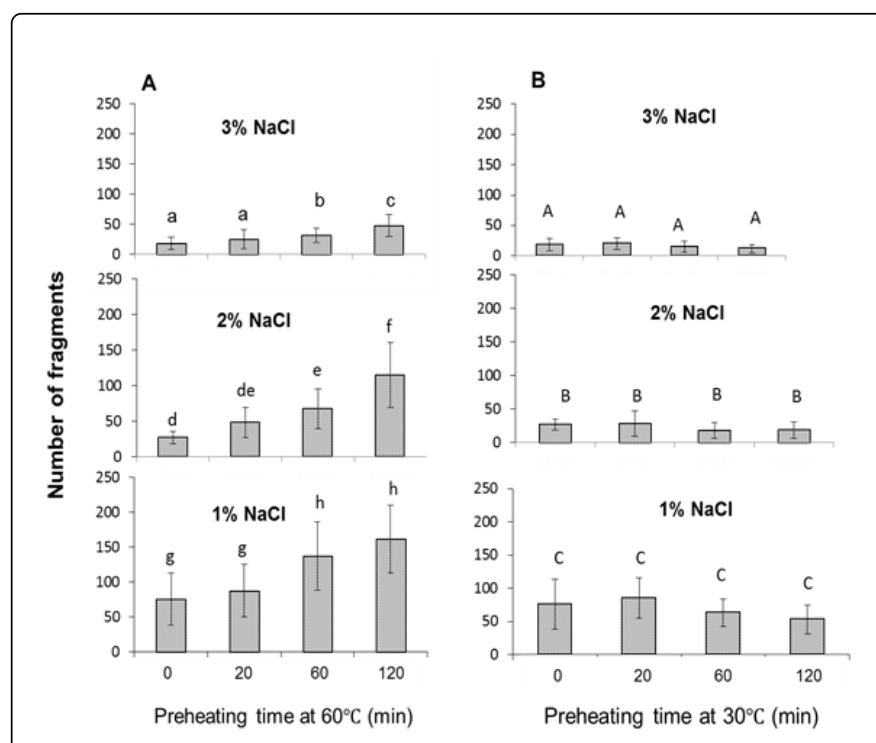

Figure 5: Number of fragments after chewing of 2-step heated surimi gels prepared with preheating at $60^{\circ} \mathrm{C}(\mathrm{A})$ and $30^{\circ} \mathrm{C}(\mathrm{B})$. Gels with different alphabetical letters differ significantly $(\mathrm{p}<0.05)$.
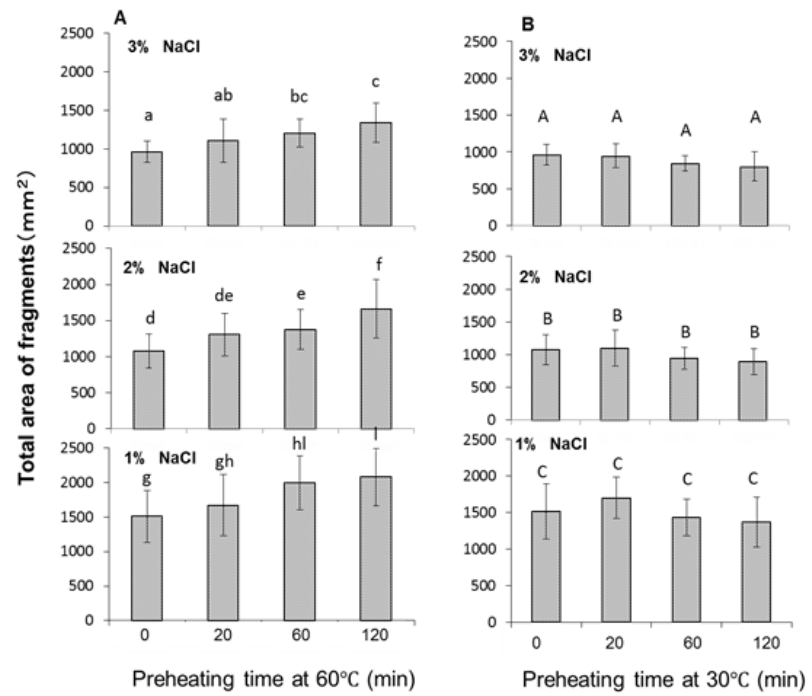

Figure 6: Total area of fragments of 2-step heated surimi gels prepared with preheating at $60^{\circ} \mathrm{C}(\mathrm{A})$ and $30^{\circ} \mathrm{C}(\mathrm{B})$. Gels with different alphabetical letters differ significantly $(\mathrm{p}<0.05)$.

In our previous investigation of the relationship between the physical properties and percieved saltiness of surimi gels prepared at $30^{\circ} \mathrm{C}$, no significant differences in percieved saltiness were observed among samples, even though gel strength was significantly affected by the setting time. In contrast, for gels pre-heated at $60^{\circ} \mathrm{C}$ in this experiment, the percieved saltiness clearly changed according to the 
Citation: Tran TMH, Kohyama K, Osako K, Okazaki E (2017) The Effect of Breaking Properties and Fragmentation on the Perceived Saltiness of Surimi Gels Prepared with Various Heating Conditions. J Exp Food Chem 3: 125. doi:10.4172/2472-0542.1000125

Page 5 of 6

heating time, and these changes were accompanied by significant changes in physical properties.

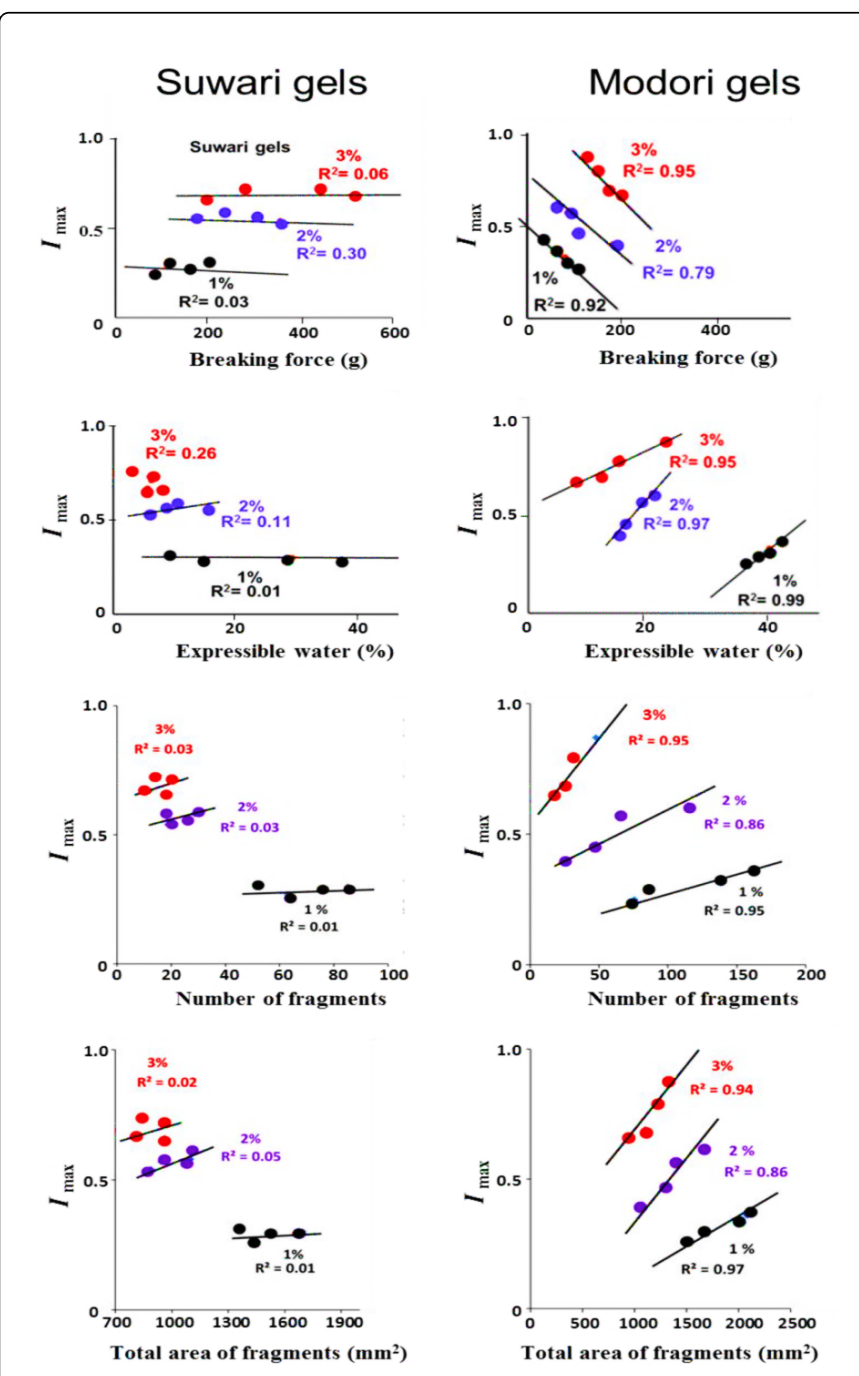

Figure 7: Relationship between maximum saltiness intensity $\left(I_{\max }\right)$ and breaking force, expressible water, number of fragments, and total area of fragments of 2-steps heated gels with various preheating time at $30^{\circ} \mathrm{C}$ (Suwari gels) and $60^{\circ} \mathrm{C}$ (Modori gels).

Based on the above-mentioned results, it was assumed that the differences in the physical properties between surimi gels prepared by preheating at $30^{\circ} \mathrm{C}$ and $60^{\circ} \mathrm{C}$ were related to the differences in percieved saltiness.

Although the elasticity of the surimi gel changes remarkably by preheating at $30^{\circ} \mathrm{C}$, the gels had a high binding capacity and were resistant to collapse, regardless of the preheating time. On the other hand, in the case of the gel preheated at $60^{\circ} \mathrm{C}$, the binding property decreased as the heating time increased. To confirm this, the fragmentation of the gels via mastication was investigated.

\section{Fragmentation of the gels}

For various gels prepared by preheating at $30^{\circ} \mathrm{C}$ and $60^{\circ} \mathrm{C}$, the levels of fragmentation in response to mastication were compared. The number of fragments and total area of fragments for each gel after mastication (10 times) are shown in Figures 5 and 6, respectively. These results clearly showed that gel fragmentation was not affected by the pre-heating time at $30^{\circ} \mathrm{C}$, but was significantly affected by the preheating time at $60^{\circ} \mathrm{C}$.

\section{Relationship between the physical properties and perceived saltiness}

The present results suggested that the level of fragmentation of the heated gel is related to the percieved saltiness. Therefore, the relationship between $I_{\max }$ and various physical parameters were examined, as shown in Figure 7.

For the gel preheated at $30^{\circ} \mathrm{C}$, there was almost no correlation between $I_{\max }$ and other parameters. In contrast, for the gel pre-heated at $60^{\circ} \mathrm{C}$, there was a strong correlation between $I_{\max }$ and other parameters. These results suggested that the progression of gel fragmentation by pre-heating at $60^{\circ} \mathrm{C}$ results in an increase in surface area and accordingly an increase in contact with taste buds in the mouth, contributing to an increase in perceived saltiness.

According to the findings in this study, it is highly likely that a significant determinant of the perceived saltiness of surimi-based products is not the strength of the gel itself, but the easiness of fragmentation. With the increase of preheating time at $60^{\circ} \mathrm{C}$, the gels separated to greater number of fragments and then produced wider surface area. The increase in the surface area increased the perceived saltiness of gels with similar salt content. Conceptual diagrams summarizing these results are shown in Figure 8.

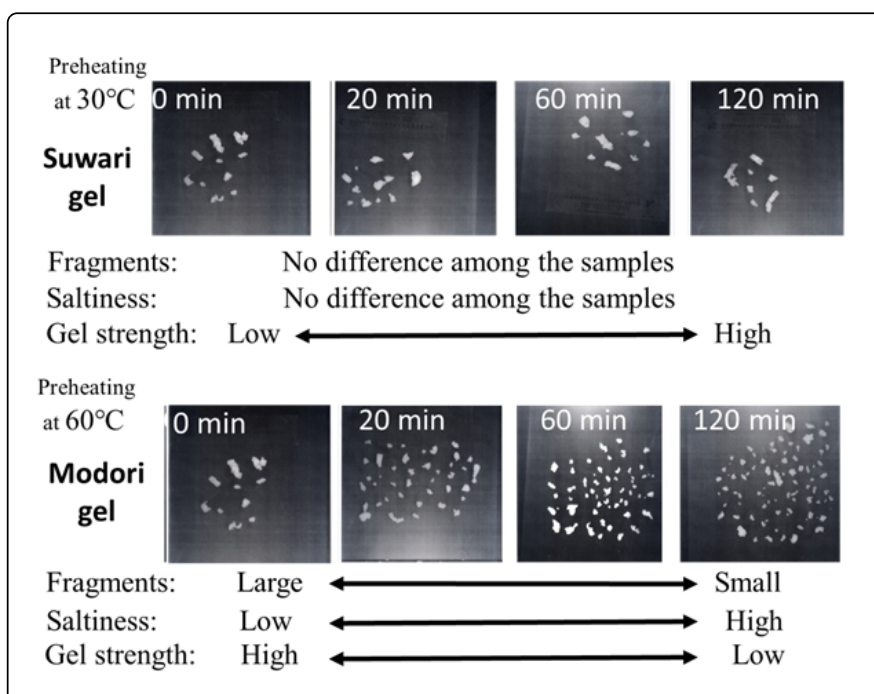

Figure 8: An example of fragments obtained from different gels after 10 times chews by a panelist.

On the other hand, it is known that the disintegration of surimi gels is considered to be induced by the proteases that are active at temperatures at temperatures of around $60^{\circ} \mathrm{C}$ [30-32] which degrade myofibrillar proteins, particularly myosin [30-32], and that various components, such as peptides and free amino acids, which is considered to affect the taste of foods, are generated accompanying with the protein degradation. Accordingly, the possibility is assumed that these components also affected the saltiness of the surimi gels. For 
Citation: Tran TMH, Kohyama K, Osako K, Okazaki E (2017) The Effect of Breaking Properties and Fragmentation on the Perceived Saltiness of Surimi Gels Prepared with Various Heating Conditions. J Exp Food Chem 3: 125. doi:10.4172/2472-0542.1000125

Page 6 of 6

this reason, further studies considering the influence of these components on taste are needed.

\section{Conclusions}

The physical properties of heat-induced surimi gels exhibited considerable differences depending on the heating time and temperature, including suwari (pre-heated at $30^{\circ} \mathrm{C}$ ) and modori (preheated at $60^{\circ} \mathrm{C}$ ). A sensory evaluation clearly showed differences in saltiness intensity among the samples. In the case of suwari gels with different heating times, there were no significant relationships between physical properties and saltiness. In contrast, in the case of modori gels with different heating times, there were clear relationships between physical properties and saltiness. These results suggested that properties related to fragmentation, rather than hardness, contribute to the perceived saltiness of surimi gels through the surface area.

\section{Acknowledgement}

The authors kindly thank Vietnamese Government through the Ministry of Agriculture and Rural Development and Vietnam International Education Development-Ministry of Education and Training for awarding scholarship to Thi My Hanh Tran. The authors would like to thank all sensory panelists from Tokyo University of Marine Science and Technology (TUMSAT).

\section{References}

1. Hutchings JB, Lillford PJ (1988) The philosophy of the breakdown path. J Text Stud 19: 103-115.

2. Tran TMH, Kohyama K, Watanabe N, Osako K, Okazaki E (2017) Relationship between the physical properties and perceived saltiness of various surimi gels prepared by different setting conditions. J Exp Food Chem 3: 2.

3. Clark R (2002) Influence of hydrocolloids on flavour release and sensoryinstrumental correlations. In Gums and Stabilizers for the Food Industry 11 (Phillips GO and Williams PA, eds.) pp. 217-224. Royal Society of Chemistry, Cambridge, MA.

4. Morris ER (1993) Rheological and organoleptic properties of food hydrocolloids. In Food Hydrocolloids, Structures, Properties, and Functions (Nishinari K and Doi E, eds.) pp. 201-210. Plenum Press, New York, NY.

5. Nakao S, Ishihara S, Nakauma M, Funami T (2013) Inhomogeneous spatial distribution of aroma compounds in food gels for enhancement of perceived aroma intensity and muscle activity during oral processing. J Text Stud 44: 289-300

6. Boland AB, Delahunty CM, Van Ruth SM (2006) Influence of the texture of gelatin gels and pectin gels on strawberry flavour release and perception. Food Chemistry 96: 452-460.

7. Plug H, Haring P (1994) The influence of flavour-ingredient interactions on flavor perception. Food Quality and Preference 5: 95-102.

8. Gillan DJ (1984) Evidence for peripheral and central processes in taste adaptation. Percept Psychophys 35: 1-4.

9. Theunissen MJ, Polet IA, Kroeze JH, Schifferstein HN (2000) Taste adaptation during the eating of sweetened yogurt. Appetite 34: 21-27.

10. Dijksterhuis DG, Boucon BC, Elodie LB (2014) Increasing saltiness perception through perceptual constancy created by expectation. Food Quality and Preference 34: 24-28.
11. Shimada A, Hatae K, Shimada A (1990) Sweetness perception of solid food. J Home Econ Jpn 41: 137-142.

12. Hayakawa F, Kazami Y, Fujimoto S, Kikuchi H, Kohyama K (2009) TimeIntensity analysis of sourness of commercially produced gummy jellies available in Japan. Food Sci Tech Res 15: 75-82.

13. Yang K, Wang Z, Brenner T, Kikuzaki H, Fang Y, et al. (2015) Sucrose release from agar gels: correlation with sucrose content and rheology. Food Hydrocolloids 43: 132-136.

14. Kohyama K, Hayakawa F, Kazami Y, Nishinari K (2016) Sucrose release from agar gels and sensory perceived sweetness. Food Hydrocolloids 60: 405-414.

15. Park JW (2014) Surimi and surimi seafood. CRC Press (3rd edn), 666p.

16. Lu FC (1970) The joint FAO-WHO Food Standards Programme and the Codex Alimentarius. WHO Chron 24: 198-205.

17. Jafarpour A, Gorczyca EM (2009) Rheological characteristics and microstructure of common carp (Cyprinus carpio) surimi and kamaboko gel. Food Biophys 4: 172-179.

18. Kobayashi N, Kohyama K, Shiozawa K (2010) Fragmentation of a viscoelastic food by human mastication. J Phys Soc Jpn 79: 44801.

19. WINROOF User Manual (2015).

20. PanelCheck User Manual (2009)

21. Luo YK, Kuwahara R, Kaneniwa M, Murata Y, Yokoyama M (2001) Comparison of gel properties of surimi from Alaska Pollock and three freshwater fish species: Effects of thermal processing and protein concentration. J Food Sci 66: 548-554.

22. Lee SK, Min BJ (2004) Effect of setting temperatures and time on the gelation properties (suwari and modori phenomena) of surimi from mechanically deboned chicken meat. Asian-Aust J Anim Sci 17: 1758-1763.

23. Arfat YA, Benjakul S (2012) Gelling characteristics of surimi from yellow stripe trevally (Selaroides leptolepis). Int Aqua Res 4: 1-13.

24. Takagi I (1973) On rheological properties and structure of kamabokoVIII. Infuence of modori upon viscoelastic properties and structure of fish muscle paste. Bulletin of the Japanese Society of Scientifc Fisheries 39: 557-562.

25. An H, Peters MY, Seymours TA (1996) Roles of endogenous enzymes on surimi gelation. Trends in Food Science and Technology 7: 321-327.

26. Benjakul S, Seymour TS, Morrissey MT, An H (1997) Physicochemical changes in Pacifc whiting muscle proteins during iced storage. J Food Sci 62: 729-733

27. Munizaga GT, Canovas GVB (2004) Colour and textural parameters of pressurized and heat treated surimi gels as affected by potato starch and egg white. Food Res Int 37: 767-775.

28. Niwa E (1992) Chemistry of surimi gelation. In Surimi technology (Lanier TC Lee CM, eds;) pp. 389- 427. Marcel Dekker: New York.

29. Alvarez C, Couso I, Tejada I (1999) Thermal gel degradation (Modori) in sardine surimi gels. J Food Sci 64: 663-637.

30. An H, Seymour TA, Wu JW, Morrissey MT (1994) Assay systems and characterization of Pacific whiting (Merluccius productus) protease. J Food Sci 59: 277-281.

31. Wang B, Xiong YL (1998) Evidence of proteolytic activity and its effect on gelation of myofibrillar protein concentrate from bovine cardiac muscle. J Agri Food Chem 46: 3054-3059.

32. Wasson D, Reppond KD, Babbitt JK, French JS (1992) Effects of additives on proteolytic and functional properties of arrowtooth flounder surimi. Journal of Aquatic Food Product Technology 1: 147-165. 